\title{
Las representaciones de Rosas en la prensa durante la primera mitad del siglo XX (1927-1954)
}

\author{
The representations of Rosas in the press during the first half of the 20th century \\ (1927-1954)
}

\author{
Leandro Nicolás Pankonin \\ leandro_pankonin@yahoo.com.ar \\ Instituto de Desarrollo Humano - Universidad \\ Nacional de General Sarmiento, Argentina \\ CONICET, Argentina
}

Recepción: 17 Octubre 2020

Aprobación: 28 Abril 2021

Publicación: 01 Marzo 2022

Cita sugerida: Pankonin, L. N. (2022). Las representaciones de Rosas en la prensa durante la primera mitad del siglo XX (1927-1954). Sociohistórica, 49, e162.

https://doi.org/10.24215/18521606e162

\begin{abstract}
Resumen: En el presente trabajo analizaremos una serie de siete encuestas que tuvieron a la figura de Juan Manuel de Rosas por tema de debate central, publicadas en distintos diarios y revistas de la Argentina entre 1927 y 1954 . El abordaje sobre dichas fuentes, entendida como una serie, nos ha brindado un cúmulo de pistas para reflexionar sobre los desplazamientos y vaivenes que se han suscitado en torno a las formas de representar a Rosas a lo largo de casi tres décadas, así como la circulación, legitimidad y tensiones que estas representaciones cobraron en cada coyuntura concreta. Por último, nos interesa, a través de esta indagación, dejar abierta la pregunta sobre cuáles pudieron haber sido los impactos que esta importante circulación de imágenes de Rosas tuvieron de cara a las décadas posteriores.
\end{abstract}

Palabras clave: Juan Manuel de Rosas, Prensa masiva, Usos del pasado.

\begin{abstract}
In this paper we will analyze a series of seven surveys that had the figure of Juan Manuel de Rosas as a central topic of debate, published in different newspapers and magazines in Argentina between 1927 and 1954. The approach to these sources, understood as a series, has provided us with an accumulation of clues to reflect on the movements and ups and downs that have arisen around the ways of representing Rosas over almost three decades, as well as the circulation, legitimacy and tensions that these representations charged in each concrete conjuncture. Finally, we are interested, through this investigation, to leave open the question about what could have been the impacts that this important circulation of images of Rosas had in the face of subsequent decades.
\end{abstract}

Keywords: Juan Manuel de Rosas, Mass media, Uses of the past.

\section{INTRODUCCIÓN}

En el presente artículo abordaremos una serie de encuestas realizadas en diarios y revistas de la prensa masiva con foco en la cuestión Rosas entre 1927 y 1954. El término utilizado -encuesta- responde a la manera en que estos sondeos de opinión fueron enunciados desde la propia prensa. La lectura que proponemos a continuación se construyó con el fin de identificar una serie de problemas que nos han permitido reflexionar sobre los desplazamientos, clivajes y tensiones que pudo haber abrigado la figura de Rosas durante este ciclo. 
Si bien la pregunta no fue siempre la misma, es dable inferir un problema último e integral, a partir del cual es posible organizar la totalidad de las encuestas. Concretamente: ¿qué representaba Rosas para cada coyuntura concreta? Nuestro trabajo consistió justamente en intentar desentrañar dicho sentido. Esta indagación puede contarse en la larga serie de trabajos que han buscado abordar los debates historiográficos en torno a la figura de Rosas, pero las fuentes que hemos elegido para hacerlo no son aleatorias. Fundamentalmente porque se trata de representaciones construidas para intervenir en la prensa, lo cual -a nuestro entendernos ha planteado posibilidades de análisis distintas a otras fuentes, restringidas al ámbito del debate entre especialistas. Y, en este sentido, cabe subrayar dos cosas. Por un lado nuestra voluntad de trabajar sobre las encuestas de manera integral, entendiéndolas como una serie que nos permita indagar el devenir de este problema en el tiempo. Y por otro lado, el hecho de tomar distancia de otras lecturas que entendemos que han reflexionado sobre la presencia de Rosas en la prensa "a la sombra", o bien de manera accesoria, de los debates entre especialistas. Si bien muchos de los que intervinieron en estas encuestas pertenecían a dicho campo, y fue ese su lugar de enunciación, el soporte en que lo hicieron esta vez garantizó una circulación mucho mayor a cualquier publicación o reunión de especialistas.

En el caso de las encuestas, los mensajes circularon entre diarios, periódicos y revistas. Entendemos que esta mediación de la prensa masiva, con todo lo que ello conlleva, resulta una fuente valiosa para reflexionar en torno al problema de los usos de Rosas en los imaginarios colectivos de la época, ya que puede haber citando a Volóshinov- "reflejado" y "refractado" los sentidos que Rosas expresó en cada caso, con un tono particular (2018, p.30). Además de permitirnos rastrear, de manera paulatina, el proceso histórico a través del cual -citando a Raymond Williams- esta figura habría dejado su lugar “residual”, en dichos imaginarios, para desplazarse a una posición "emergente" (2009, pp. 162-163). Y aquí cabe otra aclaración. El hecho de trabajar con estos materiales no significa asumir que las encuestas expresan un dato "transparente", u objetivo, del humor social con respecto a Rosas en cada época. Tal como lo ha planteado Pierre Bourdieu entendemos que el "efecto fundamental" que busca crear una encuesta de opinión es el de "constituir la idea de que existe una opinión pública unánime; por consiguiente, legitimar una política y reforzar las relaciones de fuerza que la fundamentan o la hacen posible" (1992, p. 303). En este sentido, es justamente el hecho de que efectivamente haya existido la voluntad de construir esa operación -incluso con distintas direccionalidades en cada casoel dato sobre el que, a nuestro entender, más vale la pena reflexionar. Todo lo cual, resulta en un llamado de atención sobre la centralidad que la propia prensa pudo haber tenido en el desenvolvimiento de esta cuestión.

Todo esto nos da una dimensión de masividad. Pero también -como un elemento que puede explicar en alguna medida dicha pregnancia, y su inusitado crecimiento- nos da elementos para pensar una manera posible de explicar dicho fenómeno. Nos da pistas. En ese sentido es interesante prestarle atención a quiénes organizaron las encuestas -y en ese sentido qué intereses los movieron a realizar dicha intervención-, quiénes opinaron en cada caso, cuáles fueron las asociaciones coyunturales que realizaron y por qué lo hicieron. A estos fines, hemos organizado una serie de tópicos que nos permitieron caracterizar la circulación de los usos de Rosas por distintos ámbitos: concretamente en el ámbito de la educación. Al mismo tiempo que hemos trabajado sobre las asociaciones de Rosas con el criollismo, y una saga de figuras -caras a la historia política argentina- con las que los vindicadores rosistas, así como sus detractores, establecieron un juego de espejos: fundamentalmente San Martín, Yrigoyen y Perón. En el mismo sentido, en la medida en la que el fascismo ganó relevancia en Europa -de manera creciente a partir de la década del veinte-, pasando por la experiencia uriburista local, y más aún luego del estallido de la guerra civil española, esta figura también sirvió como un mediador de carácter local sobre las distintas lecturas en torno al devenir de aquellos acontecimientos. Las encuestas con las que trabajamos fueron las realizadas por los diarios Crítica en 1927-1928, ${ }^{1} 1934^{2}$ y 1954, ${ }^{3}$ y La Época en 1948; ${ }^{4}$ y las revistas Caras y Caretas en $1933,{ }^{5}$ Aqui Está en $1939-1940^{6}$ y Esto Es en $1954 .{ }^{7}$ 


\section{APUNTES SOBRE LAS ENCUESTAS}

Tal como acabamos de exponerlo, este artículo ha sido confeccionado a base de testimonios vertidos -por distintas personalidades y de diversos modos- en una serie de siete encuestas. En tal sentido procuraremos aquí dar cuenta de las características - a nuestro entender- más salientes de las mismas, sus puntos de contacto y diferencias, así como también procuraremos aportar algunos datos sobre los medios en los que estas se desenvolvieron. Tres de las encuestas fueron publicadas en el diario Crítica. Es importante resaltar que esta modalidad de realizar un sondeo de opinión a distintas personalidades para poner en el centro del debate público determinados temas, o bien para atacar aquellos que ganaban valor en ciertos contextos, fue una práctica habitual en este diario. También vale subrayar que -si bien nos referimos al mismo medio- existen grandes diferencias entre las primeras dos de las encuestas, publicadas en los años que Crítica estaba bajo la dirección de Natalio Botana y que tuvieron muchos entrevistados en común entre una y otra; y la tercera de 1954, cuando el diario ya había pasado a manos de la editorial Haynes -y de allí, más tarde al grupo empresario ALEA - en un desplazamiento que significó -al mismo tiempo- el pasaje de ser un diario marcadamente "opositor" al peronismo, a convertirse en uno "oficialista".

La primera de estas encuestas se comenzó a publicar el 22 de diciembre de 1927 con el objetivo de "mover las opiniones de las más destacadas personalidades sobre nuestro más discutido personaje histórico”. Tal como su anuncio lo anticipaba, dicha encuesta encarnó un sondeo de las posturas que "los escritores más valiosos y conocidos, las notabilidades políticas y los artistas” tenían con respecto a Rosas. ${ }^{8}$ Cabe subrayar la popularidad que este diario tenía entonces y que la encuesta salió prácticamente todos los días de corrido entre el 22 de diciembre de 1927 y el 20 de enero de 1928. ${ }^{9}$ Más aún, dadas las referencias a la misma en los años posteriores, pareciera haber significado un parteaguas en lo que atañe al reposicionamiento público de la figura de Rosas. El propio diario remarcó que el hecho mismo de "que esta pregunta sea formulada por un periódico acostumbrado a registrar toda nueva inquietud por poco que ella se insinúe, está indicando que ese interrogante flota ya en el ambiente". Lo cual hubiese resultado "inconcebible" veinte años antes (Critica, 10 de enero de 1928, p. 9).

Seis años más tarde, entre el 5 y el 20 de julio de 1934, Crítica desarrolló una nueva encuesta en la que buscó actualizar el debate que había desplegado en sus páginas anteriormente. En los años que distaron entre una y la otra, el diario había sido clausurado por el gobierno de José Félix Uriburu el 6 de mayo de 1931, y vuelto a abrir -de la mano de la asunción como presidente de la nación de Agustín P. Justo- el 20 de febrero de 1932. La pregunta guía, esta vez, fue: “¿Deben ser repatriados los restos de Rosas?”. A modo de introducción inició la primera de estas notas haciendo alusión a la encuesta Crítica de 1927-1928, aduciendo que el "estado de espíritu" que produjera aquella encuesta "se mantiene aún y ha adquirido en estos últimos tiempos nuevo impulso por una serie de homenajes que se intentan realizar a la memoria del tirano", refiriéndose explícitamente a la tentativa de repatriación de sus restos que se encontraba en curso (Crítica, 5 de julio de 1934, p. 8).

Un año antes, a fines de 1933, se había publicado otra encuesta en el semanario Caras y Caretas, organizada por Juan José de Soiza Reilly. El tópico de la misma fue “¿Los restos de Juan Manuel de Rosas podrán ser traídos a Buenos Aires?”, y se reunió toda en un solo número. Esta revista llevaba para entonces más de treinta años de circulación, lo cual la ubicaba en un lugar distinguido en la prensa masiva de aquellos años. Esta encuesta se centró de lleno en el problema de la repatriación y, tal como la misma revista anunció, tuvo por objetivo relevar las opiniones de "ilustres hombres del país".

La revista de interés general Aqui Está, dirigida por Ramón Sopena, comenzó a publicarse, con dos entregas semanales, en abril de 1936. Tres años después, a fines de 1939, abordó desde sus páginas una encuesta sobre Rosas. Quizás el elemento más notable de la misma, a primera vista, fue que a la pregunta maniquea “¿Con Rosas o contra Rosas?”, se la acompañó con una actitud aún más maniquea de parte de la dirección de la revista: un apostillado de "rosista" o "antirrosista" definió cada una de las intervenciones en que se extendió 
"la polémica" a lo largo de tres meses. Es decir, lejos de ser este un punto de llegada que se decantara de una determinada opinión o se forjara mediante una argumentación, funcionó como un a priori. Más aún, de las veintiocho intervenciones que se desarrollaron, solamente dos se posicionaron, de manera sumamente excepcional- justificación mediante- en un campo "neutral". El criterio de elección de las personalidades a intervenir pareciera haber ido, en buena medida, en consonancia con las anteriores encuestas Crítica. Concretamente nos referimos a la adscripción de la mayoría de los encuestados al campo intelectual. Cabe agregar que hubo lugar allí también para las intervenciones de lectores de la revista. A diferencia de aquellas, que se habían instrumentado a partir de entrevistas, esta se confeccionó a partir de artículos a pedido, y la lógica del debate se estructuró -desde un principio- entre defensores y detractores.

Como característica general de las restantes tres encuestas, vale subrayar que se realizaron bajo las dos primeras presidencias de Juan Domingo Perón. ${ }^{10}$ La realizada por la revista Esto Es en 1954 compartió cierto formato común con la mayoría de las analizadas hasta aquí, en el sentido de haberse abocado a relevar principalmente las opiniones de intelectuales salientes. Si bien con tonalidades distintas, dicha encuesta como la de La Época -de 1948-y Crítica -de 1954-partieron, desde su línea editorial, de un apoyo a la repatriación de los restos de Rosas. Sin duda, en las últimas dos esa actitud fue, además, sumamente reivindicativa de su figura. Otro elemento en el que estas se diferenciaron del resto es el hecho de que la voz a la que apelaron para construir dicha reivindicación, fue "la voz del pueblo".

Con respecto a la primera de estas encuestas, vale decir que las notas se publicaron acompañadas por un interrogante central que interpelaba a los lectores: “¿Es hora de reivindicar a Rosas?” y renglón seguido se agregaba: "Abrimos nuestras columnas a la opinión de todos los argentinos". Intercalada también salió una entrevista a Manuel Gálvez, y su posterior réplica por parte de un lector. De principio a fin se mantuvo una columna que, luego de mudar de nombre varias veces, se tituló "Habla el pueblo", donde vertieron las opiniones de los lectores del diario. Dicha información llegaba al mismo mediante una boleta para recortar, que salió en prácticamente todas las ediciones de la encuesta, invitando a los lectores a participar de la "Consulta popular".

Por su parte, el diario Crítica publicó su tercera encuesta en 1954, con ciertos puntos de contacto con la realizada por La Época seis años antes. También aquí tuvieron un lugar importante las opiniones de los lectores, pero con una diferencia sustancial. La encuesta se desarrolló de manera simultánea a la campaña impulsada por la Organización Popular por la Repatriación de los Restos de Rosas (de aquí en más OPRRR), y el diario jugó, al mismo tiempo, el papel de propagandista de la misma. Es decir, Crítica -también lo hizo por esos días La Época- no solo se encargó aquí de invitar a sus lectores a participar de la encuesta dando su opinión, sino también impulsando a organizar una Junta Vecinal de la OPRRR, en cada territorio donde fuera posible, de manera tal que le diera poder territorial, visibilidad y fuerza al reclamo.

La última de las encuestas analizadas aquí tuvo lugar en la revista de interés general Esto Es, entre agosto y diciembre de 1954. ${ }^{11}$ Respecto a estas últimas tres encuestas, un dato sumamente trascendental es el hecho de que la reivindicación rosista se congenió allí con una reivindicación explicita del propio proceso político en ciernes. Si los órganos de prensa de las décadas anteriores - sea así o no- apelaron a la ecuanimidad como valor, estas otras encuestas se divulgaron en publicaciones con línea editorial peronista. Sin duda, estos son indicios tempranos de algunos de los materiales con los que sectores rosistas del peronismo pretendieron -no exentos de conflictos- insertar a Rosas, en el espejo que Perón buscó construir entre sí mismo y San Martín. Esto fue especialmente claro en la encuesta de 1948 que tuvo lugar en el diario dirigido por el entonces diputado nacional Eduardo Colom. ${ }^{12}$ Otro punto en común entre estas últimas encuestas es el hecho de que las tres se interrumpieron de manera abrupta, sin ningún indicio ni aclaración posterior en las propias publicaciones. 


\section{ROSAS EN EL ESPACIO ESCOLAR SEGÚN LAS ENCUESTAS}

Si bien existe una idea compartida de que el relato construido desde el Estado en torno a Rosas, luego de su derrota militar en la batalla de Caseros, consistió en buena medida en omitirlo, o bien en vilipendiarlo, pretendemos aquí dar cuenta de lo sucedido a partir de elementos concretos. En ese sentido, la escuela, como institución central a la hora de rastrear narrativas estatales, ha sido un vector de importancia fundamental a fin de poner en palabras los avatares de esta figura en boca de los distintos testimonios de aquellos que participaron en las encuestas. Tal como se desprende también de estos testimonios, es posible divisar el modo en que ciertos sentidos se fueron horadando con el correr del tiempo, o bien la manera en que estas formas "oficiales" de reponer el pasado convivieron tanto con otras memorias que circulaban -por ejemplo en el ámbito doméstico- y tomaban distancia de dicho relato. $\mathrm{O}$ bien aquellos que consideraban que aquel era el balance correcto sobre los acontecimientos y no había razones para modificarlos.

Alberto Palcos afirmó, en la encuesta Crítica de 1927-1928, que las "generaciones que siguieron a la de Caseros se sintieron contagiadas por esos juicios encendidos que perduraban en la atmosfera de los hogares y se respiraban en todas partes". Remarcó también que "ningún personaje de la historia nacional fue más reciamente combatido que Rosas", algo que le parecía "notorio". Ha sido como "aplastado", opinó (Crítica, 4 de enero de 1928, p. 10). En esa misma encuesta, Ángel Battistessa subrayó dos circunstancias esenciales que en su opinión impedían, a ese momento, una apreciación más ponderada y justiciera de la época de Rosas: por un lado "la tradición escolar" y por otro "la actitud de los propios historiadores". Con respecto a la enseñanza en la escuela, aseguró: "[de] Rosas y su época, en la mente del pueblo, de suyo imaginera, no queda más que una impresión fragmentaria, truculenta y teatral, una impresión en rojo mayor”. Todo esto:

deja en los chicos la sensación de que aquélla fue una época sangrienta, que retardó de un modo lamentable la organización definitiva del país. Casi sin excepción, esos mismos chicos completan luego su conocimiento de la época rosista en las páginas tan difundidas y caseras, tan románticas y tendenciosas de "Amalia" (Crítica, 10 de enero 1928, p. 10).

El Tte. Cnel. Carlos A. Aldao fustigó en 1934 a José Mármol, y a los populares folletines de Eduardo Gutiérrez, por haber consolidado la idea de Rosas como "tirano". En ese sentido afirmó estar “en una época de reivindicaciones y de justicia histórica". A esto agregó que "la empresa es ardua, pero es un deber de conciencia argentina el emprenderla y en ello estamos". Por último, bregó porque un día "el Concejo Nacional de Educación no se verá obligado a dar normas y a suspender en las escuelas el estudio de dicha época, a fin de que no sea erróneamente conocida" (Crítica, 9 de julio de 1934, p. 7). En enero de 1940, Justiniano de la Fuente - miembro de la agrupación tradicionalista "Las Bases" - intervino, luego de caracterizar la importancia y rol de la escuela como institución formadora de opinión de central importancia, y afirmó:

En cuarto grado aprendí la historia mal intencionada y unilateral de Grosso, la misma historia que aprendió mi generación. Ella contrastaba, sin embargo, con la enseñanza y el ejemplo de mi gran abuelo, que sentía devoción por don Juan Manuel y que solía cuadrarse frente a un retrato del Ilustre Restaurador de las Leyes para decirle conmovido: “¡Si volvieras!” ( $i$ Aqui Está! n 382, 15 de enero de 1940, p. 6-7).

Otro tanto señaló Tomás Ramón Alonso Marotte, quien participó en la encuesta Esto Es de 1954 en calidad de lector de la revista. Luego de presentarse como un "modesto obrero", manifestó tener el "honor de ser rosista" por "querer a mi tierra y a mi Dios”. Resaltó que Rosas, luego de gobernar veinte años, sin duda cometió también errores. Son esos errores, afirmó, los que "usaron como armas durante casi noventa años para desprestigiar el nombre de este Gran Americano y defensor de nuestra soberanía nacional”. A lo que agregó que tal cosa "sucedió con las enseñanzas al respecto, en nuestras aulas cuando éramos niños, pero ahora esos niños, por muchos miles somos rosistas" (Esto Es n ${ }^{\circ} 54,7$ de diciembre de 1954, p. 10).

Ese dispositivo escolar que unos denunciaron cada vez con mayor virulencia, era extrañado por otros que veían con cierta añoranza la vertiginosidad con la que los sentidos sobre el pasado rosista se fueron poniendo cada vez más en cuestionamiento. Ya en 1933, el entonces intendente municipal de Buenos Aires, Mariano 
de Vedia y Mitre, desde las páginas de Caras y Caretas, había observado con preocupación el hecho de que el movimiento vindicador de Rosas, que había comenzado de manera tímida, se estaba expandiendo "hasta en las cátedras de enseñanza oficial"; y con el correr del tiempo la "exaltación del tirano ha salido también a la calle" (Caras y Caretas, 23 de diciembre de 1933, n 1838, Buenos Aires, p. 19).En la misma sintonía se expresó años después -en 1940- Arturo Orgaz, al recordar con cierta nostalgia el mensaje dado por José Manuel Estrada el 24 de abril de 1877, con motivo de la muerte de Rosas, a un grupo de jóvenes estudiantes secundarios -en su calidad de rector del Colegio Nacional de Buenos Aires-. Apoyándose en aquel, afirmó:

Hoy, que no faltan profesores de colegios nacionales, del Estado y de incorporados, que desde las cátedras de historia hacen más o menos disimuladamente rosismo autentico o extranjero (totalitarismo), conviene releer esa inflamada pieza, cuya actualidad no ha pasado del todo (;Aqui Está! n³79, 4 de enero de 1939, p. 61).

En este sentido, vale traer a colación aquí el testimonio de Santiago Estrada en la encuesta Esto Es de 1954, quien fue presentado -entre otras cosas- en calidad de nieto de José Manuel de Estrada. Allí el mismo sostuvo:

¿Cómo no habría de resultar difícil un juicio sereno sobre el objeto de la encuesta? El solo nombre de Rosas trae a la memoria imágenes y recuerdos ancestrales. Narraciones truculentas de las abuelas, todavía horrorizadas de lo poco o mucho que vieran y oyeran en su infancia; vibrantes arengas contra el tirano que de la romántica generación del sesenta pasaron estereotipadas, al mundo de las frases hechas, para rodar de boca en boca en las tertulias de sobremesa y terminar, anquilosadas, en libros, revistas asambleas y escuelas públicas; y ¿cómo negarlo?, hasta la especial simpatía que despertara la figura de algún bisabuelo “lomo negro", si no rosista (Esto Es n ${ }^{\circ} 45,12$ de octubre de 1954, p. 11).

\section{Nudos DEL DEBATE SOBRE LOS USOS DEL PASADO}

En este apartado procuraremos puntualizar una serie de nudos problemáticos, presentes a lo largo de las encuestas, en los que la cuestión rosista fue haciéndose parte, así como también sus puntos de inflexión a lo largo de este ciclo, y la irrupción del revisionismo. Tempranamente, en la encuesta Crítica de 1927-1928, Buenaventura Pessolano, entonces director de la Revista de la Universidad Nacional de Buenos Aires, remarcó que todos "los pueblos tienen su leyenda negra; los argentinos tenemos la de Rosas". A lo que agregó que como "todas las leyendas negras, la nuestra no es de origen popular, sino culto, aunque su formación es de técnica populachera" (Critica, 1 de abril de 1928, p. 10). El dramaturgo, periodista, director de teatro y guionista de cine José Antonio Saldías -hijo de Adolfo Saldías, autor de la clásica Historia de la Confederación argentinaafirmó que aquella era "una buena hora para la revisión" (Crítica, 6 de enero de 1928, p. 9). Clodomiro Cordero proclamó que Rosas ya estaba "en plena rehabilitación” (Crítica, 11 de enero de 1928, p. 9). Por su parte el exdecano de la Facultad de Filosofía y Letras de la UBA Coriliano Alberini reseñó un matiz de interés sobre el tenor del debate al afirmar:

¿Rehabilitación? Es mucho decir. La pregunta, empero, ya implica todo un éxito para Rosas, pues al parecer, el asunto se ha convertido en problema. Claro está que siempre lo fue, pero ahora más que nunca. De modo que ya comenzamos a soñar con una historia de Rosas libre de apologías, requisitorias y términos medios (Crítica, 31 de diciembre de 1927, p. 17).

Ángel J. Battistesa planteó que "hasta el día de hoy la nuestra ha sido historia de partidos y, a ratos, historia de familias"; y en ese sentido es necesario que "comiencen las nuevas generaciones, desprovistas de todo criterio heredado y con imparcialidad serena, a juzgar, haciendo uso de un derecho inalienable, las acciones y valores de los hombres que prepararon la actual organización de la República”. Para sentenciar, por último, "más que oportuno, creo indispensable, la amplia rehabilitación de Rosas" (Crítica, 10 de enero de 1928, p. 9). Alfredo Monla Figueroa, quien había escrito un libro de buena estima sobre Rosas en 1911, remarcó que las "generaciones presentes y venideras son las encargadas de escribir la verdadera historia de Rosas". Entonces "la mentira quedará proscripta, el odio fallecerá" (Critica, 18 de enero de 1928, p. 9). Rómulo Carbia, por su parte, afirmó que "el Rosas de la tradición es un Rosas adulterado". Y agregó que "lo que se persigue no 
es una vindicación sino una visión real de Rosas". En ese sentido calificó el momento como una "hora de revisión". Extremó el argumento al punto de concluir que "se hace necesario desechar todo lo que se afirma sobre Rosas y estudiarlo a él y a su época totalmente de nuevo, sin más afán que el de la verdad, cualquiera que sea la que se nos haya evidenciado" (Crítica, 26 de diciembre de 1927, p. 7). En este sentido, es notable el desplazamiento de esta afirmación, cuando el mismo Carbia manifestó, en 1934: "ya no es posible desconocer que la generación presente está en la obligación de rever el juicio histórico sobre el 'Restaurador de las leyes'”. Aquello que en 1927-1928 parecía estar en gestación, tenía un tenor distinto seis años más tarde:

Hoy, cuando menos, tenemos una comprensión más humana de Rosas y su época, y podemos hacer descansar nuestras afirmaciones en pruebas que no son ni el testimonio ardoroso de nuestros padres, ni los extravagantes consejos de la leyenda que se formara en los corrillos del locuaz mulaterío.

En sintonía con una de las discusiones centrales de la encuesta 1934, afirmó “el deber imperioso de impedir que Rosas, hecho histórico del pasado, se convierta en un símbolo y sirva de bandera para la justificación de cualquier otro hecho, menos histórico y más vecino”. Así, en un intento por concluir el asunto, no falto de ambigüedad, Carbia subrayó: "creo que el juicio sobre Rosas debe ser revisto, pero repito que la repatriación de sus restos es, ahora, cosa prematura y hasta de peligro" (Crítica, 20 de julio de 1934, p. 7). Así las cosas, si en la encuesta Crítica 1927-1928 el problema de la "revisión" y la "rehabilitación" parecieran haberse planteado en términos relativos a la cuestión de la verdad, entrada ya la década del treinta este tópico se desplazó hasta acoplarse al campo de la reivindicación política. De todos modos existían ya -en la primera de estas encuestas- manifestaciones de este tipo. Manuel Gálvez directamente había embestido contra los detractores de Rosas, por exagerar "las fechorías de don Juan Manuel" (Critica, 1 de enero de 1928, p. 9). Por su parte, el radical Dardo Corvalán de Mendilharzu había anunciado que la "verdad está en marcha. Nadie es capaz de contenerla. La convicción nueva se infiltra en todos los espíritus. A lo que agregó de inmediato, que aquella era 'la hora de la vindicación de Rosas" (Crítica, 5 de enero de 1928, p. 9). Los argumentos de ese tipo fueron más tenaces en 1934. La idea de que esa coyuntura presentaba diferencias con lo sucedido hasta entonces con respecto a este debate fue clara en el testimonio de Emilio Ravignani, quien a través de su intervención de ese año afirmó: "Más de una vez se ha suscitado este apasionante problema de la repatriación de los restos de Rosas, si bien nunca con la decisión actual”. Más aún, de manera lucida llamó la atención sobre el hecho de que tal fenómeno no era un problema de hipotético futuro, sino que ya se encontraba en curso:

No niego que ello [la repatriación] pueda contribuir a que se intensifiquen las investigaciones en torno de su época con amplio y objetivo criterio. Pero ello es un movimiento que ya está en marcha; ha pasado la época en que se consideraba repudiable entrar al conocimiento del periodo que va de 1829 a 1852 . Ahora es el momento que más atrae y que reserva el mayor número de sorpresas (Crítica, 18 de julio de 1934, p. 7).

Volviendo a la encuesta Critica 1927-1928 podemos decir que si unos argumentaban aun a partir de las memorias familiares impregnadas de "pasiones", los otros afirmaban estar a la búsqueda de una historia más "verdadera", subsidiaria de los archivos y no de los odios. El propio Carlos Ibarguren resaltó un punto de inflexión entre "la antigua historia, apasionada y partidista, y la actual, lógica y averiguada". Sostuvo que la "verdadera historia en lo que respecta a Rosas no ha sido aún escrita". A lo que agregó que aquellos que "están en mejores condiciones de escribirla son los descendientes de inmigrantes que pueden asomarse al pasado sin ninguna prevención partidista o prejuicio de familia" (Crítica, 29 de diciembre de 1927, p. 9). Argumento que volvió a repetir en 1933 -ya habiendo publicado para entonces su libro Juan Manuel de Rosas: su vida, su drama, su tiempo con, al menos, seis ediciones impresas en su haber-con la premisa de que "Nuevas generaciones argentinas transformadas por el copioso aporte inmigratorio miran y analizan hoy, con ojos mucho más serenos que los de nuestros padres, al actor principal de aquella tragedia histórica” (Caras $y$ Caretas, 23 de diciembre de 1933, $\mathrm{n}^{\circ} 1838$, p. 23).

En la encuesta Aqui Está de 1939-1940 el problema del uso de las fuentes documentales o los relatos familiares, que había tenido gran protagonismo en la encuesta de 1927-1928, se desplazó a un registro 
distinto, con notables marcas de la irrupción del revisionismo en el debate historiográfico. Vale recordar que 1938 había tenido por saldo la organización de dos importantes institutos para el devenir del revisionismo en las décadas posteriores: el Instituto de Investigaciones Históricas Juan Manuel de Rosas (de aquí en más IIHJMR) y el Instituto de Estudios Federalistas (de aquí en más IEF). La identificación de un antagonismo denominado "historia oficial", caracterizado por la "conspiración de silencio" y la "falsificación del pasado" -entre otros puntos- organizó, en buena medida, de allí en más, los términos de la discusión en torno al pasado nacional en estos debates. Uno de los que intervino sobre ese punto fue, una vez más, Manuel Gálvez, quien afirmó haber llegado a un borrador de La proclama de Napostá entre los papeles que estudiaba en el Archivo General de la Nación con motivo de la escritura de su libro sobre Rosas - finalmente publicado en 1940-, y acusó a sus detractores de no haber visitado nunca ese archivo, o bien de conocerlo pero negar cierta documentación afincada allí a fin de que nunca sea leída por nadie (¡Aqui Está! n 362, 6 de noviembre de 1939, p. 6-7). Ernesto Palacio -también miembro del IIHJMR-, por su parte, compartió este diagnóstico, al afirmar que:

\begin{abstract}
El público lo ignora porque los enemigos de Rosas tienen en sus manos todo un sistema de propaganda; el monopolio, o poco menos, de la opinión pública por la prensa. En realidad, el problema no consiste ya en rehabilitar a Rosas -tarea que la investigación histórica ha realizado definitivamente-, sino en hacer conocer a todo el mundo las verdades descubiertas. Y esto es difícil, cuando se carece de los poderosos medios de difusión que poseen los adversarios ( ${ }^{A}$ Aqui Está! n ${ }^{\circ} 364,13$ de noviembre de 1939, p. 6).
\end{abstract}

En el campo diametralmente opuesto se posicionó León Rebollo Paz, descendiente del General Paz:

\begin{abstract}
La historia argentina que con insobornables probidad escribió Mitre, y que López animó con la vivacidad chispeante de su pluma, está ahí, inconmovible casi en la maciza y rica solidez de su trama. Meritorios investigadores que después de ellos vinieron, la completaron, la perfeccionaron. La rectificaron en algunos aspectos, pero el sentido de los hechos que aquéllos nos han descripto, en su interpretación medular, no ha variado sensiblemente; el espaldarazo de gloria o el estigma reprobatorio que tributaron a los personajes de los sucesos gravitan hoy con su fuerza inicial en el panorama histórico de la Nación ( $i$ Aqui Está! n 385, 25 de enero de 1940, p. 59).
\end{abstract}

En esta arena fue que los "neutralistas" eligieron intervenir con mayor tesitura. En ese sentido Emilio Ravignani afirmó que había, para entonces, "mucho, pero mucho material édito e inédito que espera una debida valoración crítica constructiva”. A lo que agregó que a fin de "penetrar debidamente en esa selva de problemas nacionales - Rosas es un problema nacional-, es necesario despojarse de toda premisa rosista o antirrosista" (;Aqui Está! n 372, 11 de diciembre de 1939, p. 39).

Llegado a este punto es interesante ver el modo en que la propia línea editorial de los diarios La Época y Crítica, al mismo tiempo que adoptaron elementos del lenguaje revisionista, buscaron construir un lugar de enunciación de síntesis mayor. En consonancia con la férrea voluntad hegemónica del movimiento peronista -sobre la cual se construyeron estos discursos- hubo aquí menos lugar para reforzar la identificación de enemigos internos y más para abogar por la unidad nacional. El 25 de enero de 1948 una carta de lectores firmada por Tito Garay- propuso una síntesis audaz: Rosas y Sarmiento. El autor de la misiva manifestó:

soy revisionista. Pero no lo soy en cuanto se evade de ese objetivo para empeñar la gloria de Sarmiento. Aun militando yo en el movimiento ideológico que más cariñosamente eleva sus inciensos a Rosas, considero equivocado el revisionismo de quienes para levantar su estatua en el país pretenden destruir otros pedestales ilustres. Soy rosista, pero también soy sarmientista. (...) Entre ambas corrientes iconoclastas debe ajustarse el juicio exacto que involucraríamos, siguiendo lineamientos revolucionarios en la tercera posición (La Época, 25 de enero de 1948, p. 12).

Seis años más tarde, el 3 de julio de 1954, una de las columnas históricas de la encuesta Crítica, subrayó:

El pueblo (...) entiende que ahora le toca el turno a Rosas en cuanto a la repatriación de sus restos, no con el propósito de abrir de nuevo apasionadas polémicas para provocar revisiones históricas. De ningún modo. Solo invoca un elemental acto de justicia hacia el denodado defensor de la soberanía argentina y la unidad nacional, que nadie, ni sus más encarnizados enemigos, ponen en duda (Critica, 3 de julio de 1954, p. 3). 
Esta misma actitud es identificable en la línea argumentativa de la revista Esto Es, que el 24 de agosto de 1954 publicó una editorial titulada "Conciliación histórica integral" en la que reconoció la devolución al Paraguay de los trofeos de la Guerra de la Triple Alianza, de parte del gobierno argentino, como "un acto de justicia". Así las cosas, el planteo continuó con la exposición de otros "dos puntos críticos" en el camino de "conciliación histórica de los vivos con los muertos". El primero de esos aludía a la repatriación de los restos de Rosas. Y en ese sentido, se afirmó: "representa, con todas sus luces y sombras, como bien lo expresó Sarmiento, el ser nacional durante el periodo en que dirigió al país". La voluntad última aquí consistía en "llegar a una verdadera conciliación" (Crítica, 3 de julio de 1954, p. 3). Rosas no solo podía ser la raíz de la discordia, sino también de la síntesis.

Este repaso da cuenta de una serie de desplazamientos de peso acaecidos en torno a la cuestión Rosas a lo largo de la primera mitad del siglo XX. Sobre todo nos permite reflexionar sobre dos elementos. En primer lugar, sobre el paulatino pasaje de una cuestión que pareciera haberse desplazado de una posición subalterna, o solapada, en la prensa masiva; a convertirse en un emergente de pujante interés en las décadas siguientes. ${ }^{13}$ Y aquí cabe la segunda reflexión, que alude al registro y el modo en el cual se fue construyendo dicha información. Concretamente nos referimos al hecho de que si bien, en un primer momento, las encuestas trabajaron sobre intervenciones de "especialistas" o figuras de peso en el quehacer nacional; a medida que avanzamos en el ciclo histórico, fueron interviniendo una cantidad de voces mayores y de extracción heterogénea, al punto de culminar en un formato de encuesta donde lo que primó -por sobre todas las cosas- fue la operación de construir la "voz del pueblo". Por último es posible rastrear los vaivenes en el modo de abordar la cuestión Rosas, desde lo "novedoso" de las primeras indagaciones, a lo crispado de las siguientes, hasta llegar a las apuestas -desde algunos sectores- por construir algún modo de síntesis entre elementos entendidos como contrarios por largo tiempo.

\section{ROSAS Y EL CRIOLLISMO}

Un elemento recurrente en los debates de la primera mitad del siglo XX en torno a Rosas -con proyección en el tiempo hacia adelante- fue cierta "función criollista". La mediación de Rosas como expresión de la nación, y/o de la patria, encontró en el imaginario del gauchaje, y su territorio natural -la pampa- un maridaje potente. Esto funcionó así incluso para muchos de sus detractores, que no pudieron dejar de envilecerse por su poderío estético. Pero también, y sobre todo, para sus vindicadores. Ricardo Rojas, en la encuesta Crítica de 1927-1928, lo había catalogado como "un sobreviviente del feudalismo en nuestra pampa”. Resaltó, sin embargo, un aspecto peculiar de sumo interés sobre su figura: su "fascinación estética" (Crítica, 24 de diciembre de 1927, p. 7). Elemento que ratificó años después en la encuesta Crítica 1934 (Crítica, 18 de julio de 1934, p. 6). En el mismo sentido, Guglielmini, parafraseando a Sarmiento, dijo ese mismo año:

Todavía hay mucho chiripa, mucha guitarra y mucho caballo. El fantasma de Rosas... Pero esos elementos debemos aceptarlos como mera temática estética, para uso e inspiración de mi amigo Borges, de Pedro Figari, y de todos los buenos artistas que quieran hacer arte del criollismo. Pero jamás como un programa de gobierno.

Más aún, explicó:

Quiero decir lo que Rosas simboliza y representa en el proceso de nuestra incorporación a la civilización occidental. Y que significa el resentimiento, la resistencia... Rosas se ha desvanecido, pero su fantasma sigue albergado en muchas almas argentinas, (...) bajo la forma de resistencia a toda incorporación de los adelantos técnicos y culturales del mundo europeo y norteamericano (Critica, 17 de julio de 1934, p. 7).

Por su parte Octavio R. Amadeo, quien había publicado recientemente un libro titulado Vidas argentinas, hizo del andamiaje criollista un elemento netamente reivindicativo: 
Juan Manuel bebió la pampa. Boleaba y domaba. Potros, ñandúes, correrías, hierras, bestias chúcaras, rodeos, enormes rebaños cerriles, pechadas. Faenas brutales que lo fortificaban y amaestraban. Aprendió a desollar y degollar, galopaba sobre los cangrejales. Y así penetró en el alma del gaucho y se identificó con ella (Crítica, 5 de julio de 1934, p. 8).

Vale subrayar que esta apelación a lo nacional operó en todo momento de la mano de un contrapunto con los que expresaban lo contrario. En 1948, mediado por las categorías que el peronismo estaba poniendo en juego, Jorge Horacio Pueyrredón -en tanto lector del diario La Época- envió una carta desde Córdoba en la que remarcó que los "que defendieron a Rosas fueron los gauchos, (...) que representaron ayer a los descamisados, así como los descamisados de hoy representan a los gauchos de ayer” (La Época, 2 de febrero de 1948, p. 12).

Seis años después es posible identificar, desde las páginas del diario Crítica -una vez más-, la premisa por la cual si unos representaban la entrega, el colonialismo y el capitalismo extranjero, Rosas, y los suyos, representaban "la soberanía e independencia de la patria, contra la intervención imperialista" (Crítica, 2 de julio de 1954, p. 3). Ese año, en otra columna del mismo diario, se lo calificó como "la voz de la autonomía criolla frente a los intereses coloniales en que se respaldaba la voracidad extranjera". A lo que agregó luego que para comprender a Rosas "hay que conocer bien al gaucho" (Critica, 28 de julio de 1954, p. 3). Como corolario, se sostuvo allí mismo que durante "los años que Rosas estuvo en el poder, mandaron los criollos en esta tierra gaucha" (Critica, 3 de agosto de 1954, p. 2).

Sea mediado por una lectura vindicadora, estética o de rechazo, pareciera ser esta la veta central por la cual la figura de Rosas se construyó como contrapunto de una forma peculiar de entender la nación. Si un lugar ocupó Rosas, para bien o para mal, ese lugar fue el de expresión de la nación criolla, del gauchaje "tierra adentro", de lo telúrico.

\section{Rosas y SAN Martín}

El trabajo de ligar a Rosas con San Martín fue la apuesta más consistente de los rosistas durante la primera mitad del siglo XX. Vale recordar que ya para los años treinta, y tal como lo ha remarcado Eduardo Hourcade, las tensas discusiones entre distintos modos de abordar el pasado nacional "convergieron" siempre en un punto: "la elevada valoración del papel sanmartiniano" (1998, p. 72). Así las cosas, el "Libertador" devenido en sinonimia del patriotismo con un consenso indiscutido, había reconocido en vida a Juan Manuel de Rosas, al punto de otorgarle su sable corvo en un acto de fuerte carga simbólica. Dicha acción, sumada a la correspondencia que medió entre ambos, fueron los argumentos corrientes sobre los que los rosistas construyeron los cimientos de ese linaje. Más aún, si dicha tematización no tuvo lugar entre los testimonios de la encuesta Critica 1927-1928, fue la operación central de la reivindicación rosista que tuvo epicentro en 1934. Ese año se constituyó la Junta Americana de Homenaje y Repatriación de los Restos del Brigadier General Don Juan Manuel de Rosas (de aquí en más JAHRRR) y su intervención más saliente -que, vale decir, existe cierto consenso en reconocerla como la primera acción reivindicativa de Rosas de envergadura en el ámbito público dentro del siglo XX- consistió en colocar un arreglo floral en la estatua de San Martin, entronizada en la plaza del mismo nombre, situada en el barrio de Retiro de la ciudad de Buenos Aires, el día 9 de julio. Un año antes se había fundado el Instituto Sanmartiniano -con sede en el Círculo Militar-. También en 1933 se había instaurado, por decreto $n^{\circ}$ 26129, al 17 de agosto como día de conmoración oficial del Estado argentino a su figura. Todo lo cual generó, en palabras de Hourcade, una "verdadera fiebre de iniciativas de conmemoración a San Martin" (1998, p. 79). Tal como lo ha afirmado Alejandro Cattaruzza, la "celebración ritual de la patria tomó perfiles específicos en los años treinta" (2001, p. 464). En ese clima, la evocación rosista apostó a insertar a su adalid en la amalgama entre la fecha de conmemoración de la independencia argentina y el "Libertador" de la patria. En consecuencia, esta forma de asociación se reflejó también en la encuesta de aquel año. Dardo Corvalán de Mendilaharzu, quien en 1929 había publicado su libro Rosas y ahora se destacaba como presidente de la JAHRRR, intervino en aquella, y subrayó 
que el solo hecho de haber anunciado el citado acto, había "herido la nube y desatado la tormenta". Pero, de manera contundente, afirmó que Rosas volvería por la "vía inmensa del mar", tal como lo quiso "el Libertador" (Critica, 5 de enero de 1928, p. 9).

La operación de vincular a Rosas con San Martín no hará más que crecer en la medida que los movimientos reivindicatorios rosistas ganen terreno en las siguientes décadas. Al mismo tiempo esta acción abrió un campo de disputa con los detractores de Rosas, que no veían con buenos ojos la construcción de un San Martin "rosista". Ricardo Rojas, quien contaba con legitimidad suficiente en la materia a raíz de la buena acogida que su libro El santo de la espada había generado entre el público lector, intervino allí. Explicó el legado del sable corvo en el hecho de que Rosas "resistió a la agresión de Francia y de Inglaterra en el Rio de la Plata (acierto del patriotismo instintivo al que no podía ser indiferente el héroe de la Independencia)" pero, sin embargo -en sus palabras- San Martín "abominó" siempre de "la obra del tirano en la política interna de su país” (Critica, 18 de julio de 1934, p. 6).

Este contrapunto asumió nuevas formas con la irrupción del peronismo en el escenario político. Aquellos rosistas que adhirieron a este movimiento utilizaron la estrategia de insertar a Rosas en el linaje que el propio Perón construyó con San Martín. Marta Philp subrayó el modo en que -durante 1950, declarado como "Año del Libertador General San Martín"- aquel apeló a la imagen del "padre de la patria”, en tanto General y conductor, a fin de erigirse a sí mismo como continuador de dicha tarea en la construcción de la nueva Argentina peronista (Philp, 2011, pp. 87-118). Pero tal como lo hemos planteado anteriormente, hubo también detractores de Perón que lo ligaron a Rosas con un sentido negativo; peronistas y sanmartinianos que no veían con buenos ojos reivindicar a Rosas; así como rosistas que no adhirieron al peronismo. Algunas de estas cuestiones serán retomadas más adelante, en el apartado dedicado a "Rosas y Perón”.

\section{Rosas e Yrigoyen}

Al momento en que se celebró la encuesta Crítica 1927-1928, la Argentina llevaba algo más que su primera década de gobiernos radicales elegidos, por primera vez, a través de las urnas. Más aún, estaba aconteciendo la campaña para acceder a la presidencia de la República durante el ciclo 1928-1934. En esa ocasión José A. Saldías sostuvo, de manera sumamente provocadora, que:

El pueblo que adoraba a Rosas no era bien hablado, pulcro, selecto. El que arrebataba a don Bartolomé Mitre sus guantes y su pañuelo en las asambleas tampoco. El que acompañó a Alem en una gran hora de la democracia era turbulento. El que grita ¡Irigoyen! es el mismo pueblo. El de Buenos Aires (Critica, 6 de enero de 1928, p. 9).

Hipólito Yrigoyen, con el sello de la UCR, fue el ganador de esa contienda tras derrotar, en las elecciones de 1 de abril de 1928, a un conglomerado de fuerzas políticas -encabezadas por el sector antipersonalista del radicalismo, pero compuesta también por el Partido Socialista Independiente y un cúmulo de partidos conservadores- denominado Frente Único. Marcelo Padoan diseccionó las formas que tomó el discurso contrario al yrigoyenismo en aquella coyuntura entre aquellos que compartían un "campo semántico" común con aquel -los antipersonalistas-, y quienes vieron en este un "fenómeno inasimilable" para la "Argentina moderna" que añoraban. Allí ubicó a sectores conservadores, nacionalistas y socialistas para los que dicho problema "traía aparejada la reapertura del conflicto civilizatorio, que pretendían ya clausurado" (2002, p. 38). Fue este un vértice del conflicto donde tomó particular vigor una forma de asociación entre Yrigoyen y Rosas. El propio diario Crítica planteó en una nota del 5 de septiembre de 1930 -con el sugestivo título de "Esto se acabó" - con respecto a Yrigoyen: “¿Qué espera para renunciar? ¿Será acaso necesario realizar el acto material de echarlo: ir a su casa, prenderlo, embarcarlo en una nave cualquiera, y darle el rumbo de Rosas?"(Crítica, 5 de septiembre de 1930, citado en Saítta, 2013, pp. 243-244). Esta forma del contrapunto se hizo más palpable aun entrada la década del treinta. En 1939, el historiador Enrique de Gandia afirmó que "el rosismo tiene una prolongación desteñida en el irigoyenismo". Luego agregó que lo que le interesa al 
historiador "es comprobar cómo, debido a causas paralelas y en cierto modo semejantes, se repite el parecido de ciertos hechos”. En ese sentido, explicó:

\begin{abstract}
Un régimen -el conservador- estaba en decadencia; produjéronse varias revoluciones; el pueblo fatigado de seguir a caudillos, escogió a uno sobre todos, y así surgió Irigoyen. En igual forma había surgido Rosas. Irigoyen, al igual que Rosas, no se apoyó en las clases aristocráticas, sino en las democráticas. Lo mismo que Rosas, supo agradar al pueblo, mostrársele cerca y, a la vez muy lejos, misterioso. También lo mismo que Rosas tuvo hacia ese pueblo un desdén soberano, y el pueblo, como en los tiempos de Rosas, se rebajó ante él hasta postrarse a sus pies. Irigoyen fue el segundo dictador de nuestra patria. El pueblo lo llevó a la dictadura. Estaba harto de engaños, de abusos, de promesas y mentiras continuas, y buscó a un hombre que vivía humildemente, que hablaba poco, que estaba rodeado de misterio, como un "adivino". Creyó en él, difundió su nombre, y más lejos estaban las gentes más veían con ilusión ese nombre lejano. Rosas e Irigoyen se mantuvieron sobre pueblos débiles y crédulos que habían descendido de su nivel moral. Las oposiciones de las minorías se estrellaban contra las masas que sólo vitoreaban su nombre.
\end{abstract}

Pero un día -manifestó de Gandia- "vino el final”. Lo que "une y asemeja en su destino a Rosas y a Irigoyen” fue que "estaban muertos antes de Caseros y antes del 6 de septiembre". A lo que concluyó:

En Caseros no hubo combate (...). El pueblo que había dado la suma del poder público a Rosas hacía mucho tiempo que ya no estaba con él y esperaba que un primer venido sepultase sus restos. Tampoco hubo resistencia el 6 de septiembre. La avenida de Mayo vio cómo el pueblo que había "plebiscitado" a Irigoyen arrastraba su busto en llamas entre silbidos. Producía compasión. Es la compasión que se siente hacia todos los dictadores que, sinceramente, se desviven por su patria y terminan presos en una isla (jAqui Está! n³67, 23 de noviembre de 1939, p. 7).

Otros sectores vieron en el yrigoyenismo la materialización de la irrupción del pueblo en la vida política nacional. En la encuesta Aqui Está de 1939 el entonces senador radical por la provincia de Santa Fe, Ricardo Caballero, afirmó: “[el] radicalismo fue, en un momento de su historia, la proyección de las ideas federales en la política argentina”. Para apuntar luego contra la "debilidad y la incomprensión de sus jefes" que:

desconocieron ese origen, y aquel gran movimiento nacional, tras el que se agitaba la esperanza argentina después de un eclipse de casi medio siglo, fue desviado hasta convertirse en un conglomerado circunstancial, de propósitos puramente electoralistas y liberales (;Aquí Está! n 370, 4 de diciembre de 1939, p. 6).

Esta asociación tomó un nuevo vuelco, años después, con la irrupción del peronismo. El lector del diario La Época Máximo G. C. Lanzalot -oriundo de Mar del Plata- intervino en la encuesta de 1948 dirigiéndose al director Eduardo Colom:

Estimado correligionario: (...) como hombre profundamente identificado con los postulados de peronistas e irigoyenistas, tengo la absoluta seguridad de la justicia de esa campaña que tuvo en el Dr. Hipólito Yrigoyen tan celoso defensor de don Juan Manuel (...) (La Época, 16 de enero de 1948, p. 16).

El contrapunto entre Yrigoyen y Rosas dio pie a una operación que más tarde tendrá sus reminiscencias entre Rosas y Perón. Nos referimos al modo de utilizar el pasado rosista, primeramente por parte de los adversarios al gobierno en cuestión, con ánimo de enhebrarlos en una tradición "oscura" de la historia nacional. Esto no quita, y hemos procurado dar cuenta de eso también, el hecho de que hayan existido asociaciones positivas entre Rosas e Yrigoyen, pero paradójicamente estas asociaciones ganaron peso luego de su derrocamiento, más aún luego de su muerte. Inclusive no faltaron sectores identificados con el yrigoyenismo que, con el ascenso de Perón, abonaron al naciente movimiento sin dejar de bregar por Rosas.

\title{
ROSAS Y EL “TOTALITARISMO”
}

El 13 de enero de 1928, Nieto P. Ibáñez, uno de los lectores del diario Crítica que intervino en la encuesta dando su opinión, catalogó a Rosas como uno de "los grandes criminales de la historia" e interpeló al diario, al afirmar que: 
Crítica fustiga en la actualidad las dictaduras de Mussolini, Primo de Rivera y del sargento Ibáñez, que en verdad son gobiernos personales fuertes pero pueden aparecer como vírgenes ingenuas comparadas con la tiranía sangrienta de Rosas (Crítica, 13 de enero de 1928, p. 13).

Con el mote de "totalitarismo" buscamos hacer referencia a una de las formas primordiales en que se hizo referencia, desde distintos sectores, a un cúmulo de experiencias políticas que fueron en ascenso en toda Europa desde la segunda mitad de la década del veinte. El prisma local sobre dichos acontecimientos se forjó sobre miradas sumamente heterogéneas. En el ámbito de las encuestas, este problema se hizo presente, sobre todo, en 1933, 1934 y con más fuerza aun 1939-1940. En 1933 el diputado socialista Augusto Bunge sostuvo que las "tentativas de rehabilitación rosista que fueron insinuadas por algunos usufructuarios o aspirantes a tales de la dictadura demagógica de Yrigoyen, y luego, del conato de dictadura plutocrática que suplantó aquella", han "caído todas al vacío". Para afirmar, a lo último, haciendo clara referencia al ascenso del fascismo en Italia, que "No hay pues motivo alguno para remover esos huesos, a no ser que alguien desee utilizarlos como fetiche de una restauración del fascismo mazorquero, puesto al revés, sustituido el poncho rojo autóctono por la espúrea camisa negra" (Caras y Caretas, 23 de diciembre de 1933, n 1838, p. 22). Así, en un solo enunciado, ligó a Rosas, Yrigoyen, Uriburu y el fascismo italiano. La cosa se hace más compleja aun si traemos a colación la intervención de Ricardo Rojas en la encuesta Crítica de 1934. El exrector de la Universidad Nacional de Buenos Aires - de postura inamovible con respecto a Rosas, y siempre sagaz en la manera de exponer sus argumentos- se había afiliado en 1931 a la UCR, identificándose con la vertiente personalista. Desde enero de ese año se habían desatado, en distintos lugares del país, una serie de sublevaciones militares conducidas por sectores del ejército identificados con el yrigoyenismo. Hacia fines de 1933, en medio de un clima cada vez más convulsionado, el presidente Justo decretó el estado de sitio. Así, varios radicales, junto con aquellos que habían participado de la insurrección de Paso de los Libres, fueron confinados a Ushuaia, entre ellos Ricardo Rojas. Con esa experiencia a cuestas, eligió intervenir en el debate en torno a Rosas con la siguiente muletilla:

Al volver de mi confinamiento en Ushuaia y de mi prisión en Martín García, lugares poco adecuados para olvidar despotismos, descubro en Buenos Aires un movimiento de propaganda para traer al país las cenizas de Rosas, primer paso hacia el perdón de la tiranía que ejerció.

Así, el nudo de su argumento apuntó a que:

Traer sus restos nada significaría, si no significara amnistiar a un tirano. El pueblo argentino debe saber que amnistiarlo, es abrir paso a sus imitadores. La historia no es sólo una ciencia de papeles, porque es también el espíritu de los tiempos en el corazón de las generaciones. Traer esos restos es despertar el espíritu que los animó (Crítica, 18 de julio de 1934, p. 6).

Alberto Gerchunoff, por su parte, inició su artículo del 28 diciembre de 1939 en la encuesta Aqui Está, con una pregunta que oficiaba así:

¿Se trata de una discusión de carácter histórico para rectificar o confirmar el juicio antagónico que se cristalizó respecto de su fuerte y extraña personalidad, o de un movimiento que tiende a rehabilitarlo y extraer de ese veredicto nuevo una regla de conducta política?

Si bien a la primera parte de la pregunta la catalogó como un “viejo asunto”, con respecto a la segunda, lanzó la diatriba "de que las consagraciones o las sentencias de la posteridad cobran el aspecto de representación", lo cual -según explicó- lo indujo "decididamente a participar en el debate suscitado". Bajo esa lupa expuso su mirada sobre el problema, y afirmó:

Se defiende en Rosas, al proyectar su rehabilitación, un método político, un procedimiento gubernativo, que consiste en el despotismo, esto es, el sometimiento unánime de los miembros de la comunidad al mando inexorable de un hombre. Y en tal circunstancia no me preocupa si Rosas fue o no un administrador escrupuloso, o si lo animaba o no ese nacionalismo que le atribuyen sus partidarios o le niegan sus enemigos. 
Rosas, con la mazorca como "su Gestapo" y siendo expresión de "el totalitarismo gaucho", resultaba "indefendible" porque "de Rosas emerge el rosismo, como del déspota emerge el despotismo" (jAqui Está! $\mathrm{n}^{\circ} 377,28$ de diciembre de 1939, pp. 6-7). Esta operación se hizo tácita en la intervención de Enrique de Gandia, quien, tras iniciar, tal como lo expusimos anteriormente, su alegato catalogando a Rosas como el "primer dictador", y tras explicar a "las dictaduras" como "un producto lógico de las "reacciones y evoluciones de la historia”, ubicó a Rosas en una saga junto a Napoleón, Hitler, Franco y Stalin. Agregó en ese sentido que la "dictadura de Rosas siguió las etapas de las dictaduras clásicas". En pocas palabras "Mussolini creó las camisas negras; Hitler las pardas; Rosas, la mazorca” (;Aqui Está! n 367, 23 de noviembre de 1939, p. 7). Con la misma lógica -y volviendo a la encuesta de 1939- algo más lejos llegó Adolfo Mitre, quien según la presentación que hizo de él la revista "mantiene con calor la tradición unitaria". Tras catalogar a Rosas, entre otras cosas, como "una sombra de pesadilla en el día luminoso", un "accidente en el devenir de la estirpe", y más aún, alguien a quien "el pueblo de Mayo" había "soterrado en los muladares del recuerdo", el contrapunto entre pasado y presente se desplazó así, en sus argumentos, hasta la afirmación -haciendo referencia al bloqueo anglo-francés-:"las fuerzas de Francia, junto a las del Reino Unido, representaban en el Plata, a mi entender, la causa de la libertad y de la civilización por la cual hoy de nuevo combaten". Así concluyó: "en el actual periodo crítico del país cambiante" la "campaña de rehabilitación de la tiranía" expresaba "cuando menos una empresa de objetivo dictatorial” ( Aqui Está! n 367, 23 de noviembre de 1939, p. 7). Otro tanto agregó González Arrilli, según la revista "antirrosista convencido":

Cada vez que he visto mover, o tratar de mover, la opinión popular alrededor de su nombre en un sentido favorable, he descubierto, con desagradable sorpresa, que no era confesable el propósito que guiaba a los promotores del "movimiento". Lo que menos interesa a los "rozistas" de la actualidad es Rozas. La defensa del indefendible personaje ha tenido, unas veces, el móvil oculto de una prédica yrigoyenista; otras veces clerical; otras fascista; actualmente "germanófila" o "hitlerista”. Los defensores de Rosas son, en su mayoría, católicos militantes, buena parte extranjeros, y partidarios vergonzantes de los regímenes de fuerza, enemigos, igual que los comunistas, de la libertad. Antiliberales que gozan -usan y abusan-del sistema liberal argentino al que quisieran destruir, nadie sabe para qué, ni por qué (¡Aqui Está! n 371, 7 de diciembre de 1939, p. 6).

Ramón de Castro Ortega se afirmó en la idea de que "la tiranía de Rosas" no logró "destruir la tradición de libertad e idealismo que caracteriza nuestra vida independiente", lo cual permitió a "nuestra patria" seguir "su trayectoria hacia sus grandes destinos" (;Aqui Está! n 381, 11 de enero de 1940, p. 61). Con la misma preocupación, Orgaz explicó que, a su parecer:

la escisión entre "rosistas" y "antirrosistas" traduce, a través de actitudes intelectuales, posiciones cívicas divergentes. Los antirrosistas forman entre los argentinos liberales y democráticos que procuran extraer la noble esencia ideológica y emocional de nuestro mejor pasado, sin duda revuelto, contradictorio y desconcertante, para reafirmar la vocación antidictatorial del país. Los rosistas, al contrario, adscriptos al totalitarismo en forma más o menos neta, extraen como suprema realidad de nuestro peor pasado la grandeza bárbara del furor autoritario, para hallar ascendencia y raíz vernácula a la pasión antidemocrática ( Aqui Está! n 379, 4 de enero de 1939, p. 6).

Sin duda los modos de representar a Rosas se transformaron al compás de las intervenciones de sus vindicadores, pero también -y esto ha sido una constante a lo largo de esta historia- de sus detractores. En ese sentido se convirtió, a través de una tradición incluso rastreable hasta los años de su propio gobierno durante la primera mitad del siglo XIX, en la representación de la irreductible barbarie argentina. Más aún, seguramente hayan sido los sectores liberales aquellos que, a fuerza de posicionar a Rosas como su antagonista, hayan abonado más a su representación como icono antiliberal. Pero si tal apelación es rastreable en un proceso de larga duración, vale remarcar que buena parte de la reactualización de esa contienda estuvo dado, para los años bajo estudio, por el ascenso del nazismo y el fascismo en el mundo occidental y el desencadenamiento de la guerra civil española primero y la segunda guerra mundial, algo más tarde-, pero también por el devenir stalinista del proceso soviético. En ese contexto, fue una operación ideológica del llamado "mundo libre" la que aglutinó a todos esos elementos dentro del denominador común del "totalitarismo". Más aún, cuando las esquirlas de ese debate irrumpieron sobre el escenario local y figuras 
como Yrigoyen o Perón fueron adosadas a la estirpe "totalitaria”, los sectores que sostenían esta posición tal como lo hemos mostrado aquí- no vacilaron en identificar a Rosas como el germen de ese "mal" en tierra argentina.

\section{Rosas y Perón}

Tal como lo adelantamos en el apartado dedicado a la asociación entre Rosas y San Martín, dicha operación tomó nuevos tonos con la irrupción del peronismo. Este elemento se hizo muy palpable a través de la encuesta de 1948, que tuvo lugar en el diario La Época, autodenominado "Órgano de la Revolución Nacional". Así fue anunciada:

La Época es un diario ARGENTINO, y por ser Argentino, Revolucionario. Como Diario Argentino y Revolucionario, reparará una gran injusticia histórica. DESDE el LUNES publicará una serie de notas dedicadas a reivindicar la Figura de don JUAN MANUEL DE ROSAS, Brigadier General y Heredero del Corvo Libertador e Invicto del GENERAL SAN MARTIN (La Época, 10 de enero de 1948, p. 16).

El 19 de enero intervino Manuel Gálvez, quien comenzó saludando al director de La Época por tener "una idea magnifica con la encuesta sobre si los restos de Rosas deben ser traídos a la patria”. Ya que así, mediante "los votos que lleguen, podremos tener un índice -aunque no de valor absoluto-, sobre los sentimientos y opiniones del pueblo acerca de don Juan Manuel”. A lo que agregó estar "convencido de que la mayoría del país simpatiza por la figura histórica de Rosas". Para eso se apoyó en "el enorme interés por los libros que refieren su obra y su vida". Esta intervención es sumamente rica para analizar los elementos sobre los que se dio, en esa coyuntura, el contrapunto entre el pasado rosista y la situación que vivía la Argentina entonces:

Hacer conocer a Rosas por el pueblo, como lo hace LA EPOCA, es obra de justicia. La historia de su tiempo fue escrita por los unitarios. Imaginémonos lo que sería la vida de Perón y la historia de su gobierno escritos por un colaborador de "Argentina Libre"...

Se introdujo así a desarrollar algunos de sus argumentos sobre la figura de Rosas, y en ese sentido aseveró: "Además de defender la soberanía y la independencia de la Patria -la independencia, si, pues los franceses pretendían colonizarnos- Rosas hizo algo más; creó la unidad nacional y el patriotismo netamente argentinos". A lo que añadió:

don Juan Manuel hizo por el gaucho, el negro y el indio -es decir por los "descamisados" de su tiempo- cuanto humanamente podía hacer. Los trató como a hombres, y los trató hasta con ternura. Fue Rosas demócrata, como hombre y como gobernante. Sus partidarios no fueron principalmente los ricos, sino los pobres. Se le llamó, como a Yrigoyen, "el padre de los pobres". Por esto y por su obra en favor del pueblo, hoy le odian los ricos, los burgueses, los extranjerizantes, los oligarcas, vale decir, los mismos que después odiaron a Yrigoyen y que hoy odian a Perón.

Y a ese juego entre pasado y presente, agregó:

que Rosas fue el precursor de Yrigoyen y de Perón en tres sentidos: en cuanto defendió la Soberanía de la Patria, en cuanto realizó obra en favor del pobre; y en cuanto propagó el patriotismo.

El pueblo verdadero, sobre todo el pueblo criollo o que se siente criollo, aunque tenga origen extranjero, debe amar a don Juan Manuel. El señaló un camino, pero los gobernantes que vinieron después, salvo Yrigoyen y Perón, no quisieron seguirlo. Prefirieron entregar al extranjero la riqueza del país y gobernar con los ricos y para los ricos.

Concluye, al final, que la encuesta en curso de La Época era "una obra transcendental, digna de que los patriotas, de que los descamisados, la admiren y la difundan” (La Época, 19 de enero de 1948, p. 16). El 10 de febrero siguiente, el diario publicó una réplica a la nota vertida por Gálvez anteriormente. La pieza guarda un valor singular porque expuso con tesón una serie de disidencias con respecto a la reivindicación de la figura de Rosas, que podían existir entre personas identificadas positivamente con el peronismo. En ese sentido Irineo Ayala empezó remarcando que "una honda conmoción", que pudo producir en su "espíritu" la nota 
en cuestión, hizo que se atreviera a contestar a Gálvez. Afirmó, refiriéndose a la batalla de Pago Largo, que en "el corazón del correntino, aún están frescas las hazañas de los secuaces de Rosas". A continuación, procuró responder, uno a uno, los puntos más salientes de la nota de Gálvez, y en ese sentido sostuvo que "si se leen los libros que tratan sobre Rosas, no es precisamente por simpatía a Rosas”. Para continuar luego señalando que no se puede comparar aquellos que estuvieron obligados a "un exilio forzoso" en tiempos de Rosas, con:

los exiliados voluntarios de hoy que combaten a Perón. Aquellos lo eran para salvar sus vidas, estos lo son por una identidad política puramente. Sin embargo, estos no le gritaron a Perón asesino y aquéllos sí. Rosas retardó el progreso argentino en 50 años; Perón lo adelantó en solo 2 años 50. Es irónico comparar queriéndose y acercarlo a Rosas (La Época, 10 de febrero de 1948, p. 12).

Esta encuesta contuvo otro tipo de intervenciones, más breves, expresadas en el diario a través de la columna "Habla el pueblo". La misma se confeccionó de opiniones llegadas al diario por telégrafo, carta y teléfono que procedieron de todas las provincias y territorios nacionales del país. La analogía entre Perón y Rosas estuvo presente en muchas de esas intervenciones. Es el caso, por ejemplo, de Roberto Ríos Salas desde Tucumán- quien afirmó que:

Rosas fue en su hora el defensor de los humildes. Les respondieron las masas trabajadoras y estas son constructivas y sinceras. Tienen el sentido providencial de la orientación. Saben distinguir y conocer a sus conductores. Juan Manuel lo fue (La Época, 13 de enero de 1948, p. 16).

O bien un grupo de obreros textiles de Avellaneda, que afirmaron:

Despierta el más cálido apoyo de los trabajadores peronistas la feliz iniciativa suya en favor de la repatriación de los restos de la magna figura de don Juan Manuel de Rosas. Los descamisados de hoy con los colorados de ayer: ambos representan las fuerzas populares en lucha contra la oligarquía, tan antinacional antes como ahora (La Época, 18 de enero de 1948, p. 12).

Otra de las opiniones que tuvo un lugar nada deleznable en el debate fue la de aquellos que, si bien identificados con el proceso político en desarrollo, y valorando positivamente la posibilidad de una repatriación, entendieron que el contexto que atravesaba la Argentina, y más concretamente el futuro escenario electoral, no era propicio para dicha acción. Fue el caso, por ejemplo, de Amancio González (que envió su carta desde Tucumán), quien afirmó no creer oportuno el momento, por ser "vísperas electorales", ya que los "contreras van a tomar ese tema para sus discursos con mala fe" (La Época, 12 de enero de 1948, p. 16)

Vale subrayar también el hecho de que aparecieron vertidas allí opiniones diversas, tanto de lectores no identificados con el peronismo, lectores identificados con el peronismo pero no con reivindicar a Rosas, como de lectores peronistas y rosistas. El 19 de enero, Salomón Abollinsky aseveró:

Desenterrar la figura odiosa del Restaurador solo servirá para exacerbar aún más el espíritu agresivo de ciertas conciencias nacionalistas, en momentos en que más que nunca el país necesita abrazos y capitales extranjeros (La Época, 19 de enero de 1948, p. 16).

Por su parte el señor Lavalle Lezica, quien calificó de improcedente la reivindicación de Rosas, agregó como argumento el hecho de que "solamente arrastraba a los estratos inferiores de la sociedad porteña", mientras que lo "mejor y más granado de la misma, militó desde un comienzo en las filas de sus adversarios" (La Época, 14 de enero de 1948, p. 16). Rafael Petersen contestó esta carta con las siguientes palabras: "el pueblo, el verdadero pueblo, ese 'estrato inferior', ese 'aluvión zoológico', esa 'masa sudorosa', esos 'descamisados', representan la voluntad de Dios”. Y de inmediato añadió: “los que no formamos parte de lo 'más granado' estamos con Rosas. Que también nosotros, pobre 'estrato inferior', estuvimos con la Patria y con Perón el 17 de octubre y el 24 de febrero" (La Época, 16 de enero de 1948, p. 16). En el mismo sentido se pronunció el entonces diputado nacional peronista, y vicepresidente de la cámara baja, Joaquín Díaz de Vivar, quien manifestó en la encuesta Esto Es de 1954 respecto de Rosas: 
Fue un patricio representativo, no obstante ello, de las masas populares, y cuyo cesarismo democrático (y todo cesarismo siempre lo fue) marca la pauta de nuestra democracia en agraz. Sus antagonistas unitarios fueron liberales, pero no democráticos; "progresistas", pero impopulares; deseosos de imponer su marbete al "país oficial”, pero finalmente derrotados por el pueblo que conducía Rosas, cuyo gobierno forjó al país, afianzando la unidad nacional (Esto Es n ${ }^{\circ} 44,28$ de septiembre de 1954, p. 9)

El juego de espejos entre Rosas y Perón a través de las encuestas englobó una serie de elementos importantes. Por un lado el hecho de que la metodología a la cual apelaron los medios que la llevaron a cabo buscaron al mismo tiempo, relevar y construir un sentido positivo sobre Rosas de cara a un público masivo. Pero si esto resultó un elemento novedoso, cabe agregar que dicha ponderación no fue en abstracto, sino que se asentó sobre la construcción de una tradición política en la que Rosas se propuso como un eslabón pasado de ese propio presente. Más aún, la explícita intencionalidad de las encuestas, su interrupción estrepitosa, dan cuenta a nuestro entender de la existencia de un campo de disputa sobre los alcances, o no, de esta amalgama, al interior del primer peronismo.

\section{Conclusiones}

A fines de 1927 y principios de 1928, poner en jaque ciertos sentidos sedimentados en torno a Rosas, y abrir una discusión sobre su posible "rehabilitación”, significó algo ciertamente rupturista y debatible. Para 1934 lo eruptivo de las posiciones rosistas llevó a más de uno a llamar la atención sobre una situación sin precedentes. Pero unos años más tarde, en la encuesta Aqui Está de 1939-1940, parecía haber solo dos campos donde estar parado. Lo que había que explicar era más bien la neutralidad. Más aún, las encuestas del ciclo peronista se apropiaron de cierto lenguaje revisionista y asumieron un posicionamiento claramente rosista. ¿Qué sucedió a lo largo de esas tres décadas? Las encuestas, y concretamente el interés de los editorialistas a incluir esta problemática en sus revistas o diarios, reflejó el creciente interés que cobró este tema en la sociedad en esos años.

Tal como hemos intentado mostrar aquí, creemos que, en buena medida, fue a partir de un complejo encadenamiento de asociaciones - bien sea para reivindicarlo, o para difamarlo- que la figura de Rosas se fue convirtiendo en un engranaje, con un lugar de importancia creciente en el imaginario popular de la nación, durante la primera mitad del siglo XX. Pero, de manera simultánea, esas encuestas también refractaron y construyeron sentido sobre los imaginarios colectivos en torno a la figura de Rosas.

Si bien se puede decir que muchas de las voces que intervinieron en estos debates son las mismas que protagonizaron el enfrentamiento entre liberales y revisionistas, vale remarcar que hubo muchas otras que no. Y este punto nos lleva a una segunda conclusión. Allí también participaron figuras como Paul Groussac, Héctor P. Blomberg, Justiniano de la Fuente, el ídolo racinguista -y tricampeón de las temporadas 1949, 1950 y 1951 - José Manuel García Pérez o Alberto Vaccarezza. Esto quiere decir, a nuestro entender, que una diversidad de voces era necesaria a fin de alcanzar un tono "real" del humor social en torno a este problema. Más aún, cuando las encuestas, durante los gobiernos peronistas, asumieron un carácter más reivindicativo, este problema asumió formas distintas. A la disputa reivindicatoria de la figura de Rosas se le sumó, desde nuestro punto de vista, una intencionalidad aún más audaz: interpelar al propio Perón para que asuma a Rosas como pasado de su propia tradición. Pero si esta era una iniciativa propia de un sector del peronismo, parece no haber sido capaz - aún- de convertirse en hegemónica. Más bien, por el contrario, tal como lo remarcamos anteriormente, las dos encuestas publicadas en medios oficiales -así como la publicada en la revista $E s t o E s-$, y con una vocación fuertemente rosista, dejaron de salir de un día para el otro sin aviso previo. Y el mismo año que la segunda de estas encuestas se publicó, el Manualperonista -confeccionado bajo la responsabilidad del Consejo Superior del Partido Peronista- prescribió, en uno de sus pasajes, "Adoptar medidas para evitar [que] el Partido intervenga o aparezca interviniendo a través de sus dirigentes o afiliados en los problemas de revisionismo o antirevisionismo histórico" (1954, p. 386). ${ }^{14} \mathrm{Si}$ bien la historia de este 
vínculo sufriría profundas metamorfosis, contó ya en aquellos años con un lugar no menor en los debates de propios y ajenos- sobre las carnaduras del peronismo.

En este punto cabe traer a colación los contrapuntos entre Rosas e Yrigoyen, ya que tanto en este caso, como en el de Perón -aunque de maneras muy distintas-, le cupo a los antagonistas a estos movimientos un rol muy importante a la hora de usar el pasado para intervenir sobre el presente. Si en el caso de Yrigoyen fueron bastante tenues los usos de Rosas, en clave reivindicativa, para bregar por él, en el caso de Perón, y del peronismo como movimiento sumamente heterogéneo, aquello que en los años de sus primeros gobiernos no tuvo un lugar hegemónico -aunque sí claramente una importante articulación de expresiones- ocupó un lugar distinto en la estrategia ideológica de la resistencia, luego de que la autodenominada "revolución libertadora" hiciera loas de la tradición Mayo-Caseros para señalar a su contrincante como encarnación de la "segunda tiranía".

Creemos que el repaso de la historicidad de estas voces, así como sus formas de asociación con cada coyuntura, sumado a un cúmulo de memorias que fueron encontrando -o no- vetas habilitadas para expresarse, dan cuenta del modo en que la cuestión rosista fue ganando gradualmente terreno en los debates públicos de la primera mitad del siglo XX. Y si bien el revisionismo, como tal, ocupó un lugar de importancia en esa contienda, lejos está de corresponderle la explicación total del problema. Hubo, más bien, un (o quizás correspondería decir unos) "rosismo popular" hecho de materiales diversos -y hasta contradictorios-y experiencias disímiles, que cambió sus maneras de representarse -y también de ser representado-, y concretó sus formas de articulación de manera cambiante, dependiendo de la relación de fuerzas que cada coyuntura planteó. Si Rosas se constituyó en un símbolo con creciente peso durante la década del sesenta, eso se debió -creemos- a las formas de acople que el rosismo y el peronismo supieron forjar en la Argentina que nació el 16 de septiembre de 1955. Pero también, sin dudarlo, a todo aquello que venía de antes.

\section{Bibliografía:}

Bourdieu, P. (1992). La opinión pública no existe. Debates en Sociología, 17, 301-311

Cattaruzza, A. (2001). Descifrando pasados: debates y representaciones de la historia nacional. En A. Cattaruzza (Dir.), Crisis económica, avance del estado e incertidumbre politica (1930-1943). Buenos Aires: Sudamericana.

Gálvez, M. (1945). Vida de Hipólito Yrigoyen. Buenos Aires: TOR.

Hernández, P. J. (1978). Conversaciones con José María Rosa. Buenos Aires: Colihue/Hachette.

Hourcade, E. (1998). Ricardo Rojas hagiógrafo (a propósito de El santo de la espada). Estudios sociales, 15.

Consejo superior del Partido Peronista (1954). Manual del peronista. Consejo superior del Partido Peronista: Buenos Aires

Padoan, M. (2002).Jesús, el templo y los viles mercaderes: un examen de la discursividad yrigoyenista. Bernal: Universidad Nacional de Quilmes.

Philp, M. (2011). Conmemorar a San Martín: Historias/memorias nacionales y locales durante el primer peronismo. En M. Philp (comp.), Intervenciones sobre el pasado. Córdoba: Alción Editora.

Saítta, S. (2013). Regueros de tinta. El diario Critica en la década de 1920. Buenos Aires: Siglo XXI.

Volóshinov, V. N. (2018). El marxismo y la filosofía del lenguaje. Buenos Aires: Godot.

Williams, R. (2009). Marxismo y literatura. Buenos Aires: Las cuarenta.

\section{Notas}

1 Participaron: Ricardo Rojas (24 de diciembre), Emilio Ravignani (25 de diciembre), Rómulo de Carbia (26 de diciembre), Carlos Correa Luna y Miguel Sussini (27 de diciembre), Diego Luis Molinari y Jacinto Carranza (28 de diciembre), Carlos Ibarguren y Agustín Rodríguez Arraya (29 de diciembre), Arturo Capdevilla y Héctor Ramos Mejía 
(30 de diciembre), Alberto Gerchunoff y Coriliano Alberini (31 de diciembre), Manuel Gálvez y José de España (1 de enero), Paul Groussac y N. V. Lascano (2 de enero), Luis Pascarella y Alcides Greca (3 de enero), Alberto Palcos y B. J. Pessolano ( 4 de enero), Dardo Corvalán Mendilatrarzu y Nicolás Olivari ( 5 de enero), José Antonio Saldías (6 de enero), José León Suárez (7 de enero), Clemente Ricci (8 de enero), Jorge Sagastume y Arturo Mallié (9 de enero), Ángel Battistessa y Enrique Tornú (10 de enero), Clodomiro Cordero (11 de enero), Mario M. Guido (12 de enero), David Farina Ortiz y Nieto P. Ibañez -lectores- (13 de enero), C. Ibarra, A. R. Beraedone y Carlos A. Gil-lectores- (14 de enero), Fernando A. Coni Bazan (15 de enero), Lucio Moreno Quintana (17 de enero), Alfredo Monla Figueroa y Rafael M. Parravicini (18 de enero), y un artículo de síntesis (20 de enero).

2 Participaron: Octavio R. Amadeo ( 5 de julio), Dardo Corvalán de Mendilaharzu (7 de julio), Carlos A. Aldao ( 9 de julio ), Clodomiro Cordero (11 de julio), Homero M. Guglielmini17 (de julio), Ricardo Rojas (18 de julio), Emilio Ravignani (19 de julio) y Rómulo D. Carbia (20 de julio).

3 Participaron: Alberto Vacarezza (16 de julio), José Manuel García Pérez (17 de julio), Iris Marga (19 de julio), Timoteo Farías (23 de julio), Jorge F. Perrone (25 de julio), Luis Soler Cañas (27 de julio) y José Manuel Buzeta (30 de julio).

4 Se desarrolló el 12 de enero y el 16 de febrero de 1948.

5 Participaron: Mario de Vedia y Mitre, Antonio Sagarna, Eusebio Gómez, Augusto Bunge, Carlos Ibarguren, Alfredo L. Palacios, Juan Cafferata, Marcos Ezcurra, Juan Mármol y Ricardo Rojas.

6 Opinaron: Manuel Gálvez ( 6 de noviembre de 1939), Arturo Capdevila (9 de noviembre), Ernesto Palacio (13 de noviembre), Benjamín Villegas Basavilvaso (16 de noviembre), Ricardo Font Ezcurra (20 de noviembre), Enrique de Gandia (23 de noviembre), Julio Irazusta (27 de noviembre), Héctor P. Blomberg (30 de noviembre), Ricardo Caballero ( 4 de diciembre), B. González Arrilli (7 de diciembre), Emilio Ravignani (11 de diciembre), Ramón Doll (14 de diciembre), Adolfo Mitre (18 de diciembre), Diego L. Molinari (21 de diciembre), José Antonio Saldías (25 de diciembre), Alberto Gerchunoff (28 de diciembre), Carlos Steffens Soler (1 de enero de 1940), Arturo Orgaz (4 de enero), Roberto de Laferrere (8 de enero), Ramón de Castro Ortega (11 de enero), Justiniano de la Fuente (15 de enero), Julio E. Donato Álvarez (18 de enero), Mariano G. Bosch (22 de enero), León Rebollo Paz (25 de enero), Lectores (29 de enero), Lectores (1 de febrero).

7 Opinaron: Jorge Lavalle Cobo y Joaquín Díaz de Vivar (28 de septiembre), Manuel Gálvez y Enrique De Gandia (5 de octubre), Ricardo Piccirilli y Santiago de Estrada (12 de octubre), Enrique Canevari (26 de octubre), Alberto Ezcurra Medrano y Vicente Cacuri ( 9 de noviembre), María Raquel Adler y Dionisio Schoo Lastra (23 de noviembre) y Fermín Arenas Luque y Tomás R. Alonso Marotte (7 de diciembre).

8 Crítica, 22 de diciembre de 1927, p. 2. Cabe aclarar que si bien la primera aproximación a esta encuesta, así como a la correspondiente al año 1934, fue hecha a través del Fondo de Recortes Ravignani (Varios, Tomo I y II) asentado en el Instituto de Historia Argentina y Americana "Dr. Emilio Ravignani”, FFyL-Universidad de Buenos Aires, para los fines de esta investigación hemos trabajado directamente con el diario de manera tal de poder completar toda la serie de la encuesta, cubriendo algunos faltantes en aquel.

9 Si bien no hemos hallado información concreta sobre los niveles de circulación de los ejemplares que contuvieron la encuesta Crítica a la que nos referimos aquí, existen una serie de análisis y comentarios sobre el rol que este diario jugó en el triunfo electoral de Yrigoyen en 1928 -así como en su caída dos años después-, que dada la contemporaneidad -entre estos hechos y la encuesta en cuestión- nos resultan de mucho valor para reflexionar sobre el lugar que Crítica tenía entonces en la "opinión pública”. Manuel Gálvez puso en un lugar central a este diario, a la hora de explicar las razones del triunfo de Hipólito Yrigoyen en las elecciones aquel 1928, y lo planteó de este modo: "En el triunfo de Yrigoyen ha intervenido decisivamente un factor de excepcional importancia. Sus méritos, su habilidad política, el amor de cierta parte del pueblo, no hubieran obrado sobre la vasta masa neutral de no haber contado con el necesario vehículo de propaganda. Seiscientos mil hombres, por lo menos, de los que votaron por Yrigoyen, ya que apenas el resto estaría afiliado al radicalismo, no se hubieran enterado de cuanto había que enterarse sin el diario que hizo triunfar al candidato del pueblo. (...) Para lograr tan enorme concurso de votos es necesario el periódico que cotidianamente, en tiradas de doscientos o de trescientos mil ejemplares, difunda por todos los rincones del país los méritos del candidato y los defectos del contrario". A lo que agregó algunas líneas más adelante, con respecto a Crítica, "su aptitud para hacer célebre a cualquiera y para hundir a cualquiera” (Gálvez, 1945, pp. 317-318). Pero para tomar más dimensión aun del lugar que dicho diario ejercía sobre la opinión pública de la sociedad de entonces, vale decir que -tal como Gálvez lo había remarcado- Saítta ha subrayado el rol central que Crítica tuvo también en la caída de Yrigoyen dos años después, en septiembre de 1930, cuando llegó a poner en circulación el numero de 10.603.269 ejemplares (Saítta, 2013, p. 246).

10 Un elemento sobre el cual vale llamar la atención, es el hecho de que recién en la encuesta Crítica de 1954 y Esto Es, del mismo año, se dan las primeras participaciones de mujeres en esta serie.

11 Cabe aclarar que si bien la primera aproximación a esta encuesta fue hecha a través del trabajo de Darío Pulfer (2015). La revista Esto Es y el debate por la repatriación de los restos de Rosas en las postimetrías del peronismo clásico. Buenos Aires: Peronlibros. A los fines de esta investigación hemos trabajado directamente con la revista en cuestión. De aquí en más citaremos el material de primera mano. 
12 Por una cuestión de espacio, no hemos utilizado aquí la entrevista realizada por Luis Alberto Romero a Eduardo Colom en 1972, asentada en el Archivo Oral de la Universidad Torcuato Di Tella, donde es posible ampliar elementos importantes. Ver: "Entrevista a Eduardo Colom", Historia Oral, Archivo Di Tella, Universidad Torcuato Di Tella, 1972.

13 En 1973 la revista Gente sacó una nota haciendo referencia a la encuesta Crítica 1934 y reponiendo sus intervenciones como un hito en los debates sobre la repatriación de Rosas. Ver: Gente, 4 de enero de 1973, pp. 26-29, en: AR-BNMMARCH-ESAR-CRO-ARCH, sobre n AR00103112 (Juan Manuel de Rosas -sus restos-).

14 Es importante remarcar también que este problema no figuró como tal en la primera edición del "Manual" de 1948 (ver: Manual del peronista. Buenos Aires: Consejo superior ejecutivo del Partido Peronista, 1948). José María Rosa al ser consultado por el apoyo -o no- del peronismo al rosismo, durante su gestión de gobierno, afirmó respecto a esta cuestión: "El que después fue vicepresidente, Tessaire, que era liberal y antirrosista, prohibió a los afiliados peronistas inscribirse en institutos rosistas. Por supuesto que los mejores no lo cumplieron. También nos perseguía el ministro del interior, Borlenghi, que también era liberal. Pero tuvimos apoyo, en los últimos años, del gobernador Aloé. Parece mentira, pero fuera de Aloé, el único gobernador peronista que apoyó el rosismo, solo Manuel Iriondo, regiminoso, en Santa Fe de 1938, lo había apoyado. Sin embargo en tiempos del peronismo nos dejaban pegar carteles, cosa que después no se pudo hacer (...)”. (Hernández, 1978, p. 127). 